\title{
Quality of life in subjects with upper- and lower-limb spasticity treated with incobotulinumtoxin $A$
}

Klemens Fheodoroff ${ }^{*}$ (D), Tiina Rekand ${ }^{2}$, Luisa Medeiros ${ }^{3}$, Peter Koßmehl ${ }^{4}$, Jörg Wissel ${ }^{5}$, Djamel Bensmail ${ }^{6}$, Astrid Scheschonka ${ }^{7}$, Birgit Flatau-Baqué ${ }^{7}$, Olivier Simon ${ }^{8}$, Dirk Dressler ${ }^{9+}$ and David M. Simpson ${ }^{10 \dagger}$

\begin{abstract}
Background: We evaluated quality of life among subjects with upper- and lower-limb spasticity who received escalating doses of incobotulinumtoxinA (total body doses up to $800 \mathrm{U}$ ) in the prospective, single-arm, dose-titration TOWER study.
\end{abstract}

Methods: In this exploratory trial, subjects ( $N=155 ; 18-80$ years of age) with upper- and lower-limb spasticity due to cerebral causes who were deemed to require total body doses of up to $800 \mathrm{U}$ incobotulinumtoxinA received three consecutive injection cycles of incobotulinumtoxinA (400,600, and up to $800 \mathrm{U}$ ), each with 12 to 16 weeks' follow-up. QoL was assessed using the EuroQol 5-dimensions questionnaire, three-level (EQ-5D), before and 4 weeks post-injection in each injection cycle and at the end of injection cycle 3.

Results: The mean EQ-5D visual analog scale scores of 155 participants continuously improved from study baseline to 4 weeks post-injection in all injection cycles (mean [standard deviation] change 6.7 [14.1], 9.6 [16.3], and 8.6 [17.0] for injection cycles 1, 2, and 3, respectively; $p<0.0001$ for all, paired sample t-test). In general, among those with a change in the EQ-5D rating of their condition, the proportion of subjects with 'improvement' was greater than that with 'worsening' for individual EQ-5D dimensions across all injection cycles. At the end of injection cycle 3, the proportion of subjects rating their condition as 'normal' increased from study baseline for all dimensions, and there was $a \geq 46 \%$ reduction in the proportion of subjects with a rating of 'severe impairment'.

Conclusion: These preliminary results suggest that escalating incobotulinumtoxinA doses up to $800 \mathrm{U}$ are associated with improvement in quality of life ratings in subjects with multifocal upper- and lower-limb spasticity, and form a basis for future comparator studies.

Trial registration: ClinicalTrials.gov, NCT01603459. Date of registration: May 22, 2012.

Keywords: Botulinum neurotoxin, IncobotulinumtoxinA, Long-term care, Lower limb, Quality of life, Spasticity, Spasticity management, Upper limb

\footnotetext{
* Correspondence: klemens.fheodoroff@kabeg.at

${ }^{\dagger}$ Dirk Dressler and David M. Simpson contributed equally to this work.

${ }^{1}$ Gailtal-Klinik, Hermagor, Austria

Full list of author information is available at the end of the article
}

(c) The Author(s). 2020 Open Access This article is licensed under a Creative Commons Attribution 4.0 International License, which permits use, sharing, adaptation, distribution and reproduction in any medium or format, as long as you give appropriate credit to the original author(s) and the source, provide a link to the Creative Commons licence, and indicate if changes were made. The images or other third party material in this article are included in the article's Creative Commons licence, unless indicated otherwise in a credit line to the material. If material is not included in the article's Creative Commons licence and your intended use is not permitted by statutory regulation or exceeds the permitted use, you will need to obtain permission directly from the copyright holder. To view a copy of this licence, visit http://creativecommons.org/licenses/by/4.0/ The Creative Commons Public Domain Dedication waiver (http://creativecommons.org/publicdomain/zero/1.0/) applies to the data made available in this article, unless otherwise stated in a credit line to the data. 


\section{Introduction}

Disabling spasticity of the upper and lower limbs is a common and often painful complication of stroke and results in marked limitations of subjects' mobility and their ability to perform routine daily tasks, such as dressing and personal hygiene [1-5]. These effects have an impact on subjects' quality of life (QoL), with many subjects reporting dependence on family and carers, social isolation, and depression [1, 2, 6, 7]. Improvement in QoL is often a key goal for subjects with spasticity [1]; QoL measures should therefore play a vital role in the assessment of clinical interventions.

Botulinum neurotoxin type A (BoNT-A) formulations are recommended in general spasticity guidelines for the treatment of focal spasticity of the upper and lower limbs $[8,9]$. The efficacy and safety of treatment with BoNT-A formulations in subjects with focal spasticity are well established [10-19]. However, treating multifocal upper- or lower-limb spasticity may require total doses of BoNT-A higher than those currently approved, in order to meet subjects' clinical needs and goals of rehabilitation therapy [20].

Previous data have indicated the immunologic and toxicologic safety of incobotulinumtoxinA doses up to 1200 mouse units in subjects with spasticity or dystonia [21]. Recommendations of incobotulinumtoxinA for upper-limb spasticity include $\leq 400 \mathrm{U}$ per session in the United States and $\leq 500 \mathrm{U}$ per session in the European Union, no more frequently than every 12 weeks $[22,23]$. The prospective, single-arm, dose-titration TOWER study was designed to assess the safety and efficacy of escalating incobotulinumtoxinA doses (total body doses of $400 \mathrm{U}, 600 \mathrm{U}$, and up to $800 \mathrm{U}$ ) in adults with multifocal spasticity of the upper and lower limbs, on the same body side, as a result of stroke or other cerebral causes [20]. With regards to safety, the incidence of treatment-related adverse events did not increase with escalating incobotulinumtoxinA doses up to $800 \mathrm{U}$. Dose escalation improved muscle tone, with mean improvements in Resistance to Passive Movement Scale (REPAS) [24] scores at 4 weeks post-injection of -4.6 , -5.9, and-7.1 for consecutive injection cycles with $400 \mathrm{U}, 600 \mathrm{U}$, and up to $800 \mathrm{U}$, respectively (all $p<0.0001$, Student's t-test for paired samples) [20].

While the safety and efficacy of BoNT-A treatments are well reported, data on subjects' QoL following BoNT-A treatment remain limited and largely inconclusive $[1,3$, 25 ], with extremely limited data available to date on QoL following combined treatment of upper-and lower-limb spasticity [1]. Furthermore, few studies report baseline scores for QoL in untreated subjects with spasticity [3, 4], leading to a lack of normative data for comparison. In order to address this knowledge gap and to better understand the effects of escalating incobotulinumtoxinA treatment on subjects' QoL, we report QoL outcomes based on the EuroQol 5-dimensions questionnaire, threelevel (EQ-5D) [26, 27], following incobotulinumtoxinA treatment of upper- and lower-limb spasticity in the TOWER study.

\section{Methods}

Study design

TOWER (The Titration study in lOWer and uppER limb spasticity; NCT01603459) was a prospective, single-arm, multicenter, non-randomized dose-titration study investigating the safety and efficacy of incobotulinumtoxinA in subjects with upper- and lower-limb spasticity who were deemed by the investigator to require total body doses of $800 \mathrm{U}$ incobotulinumtoxinA. The study was conducted at 30 centers in Europe and North America. To minimize potential bias of subject-rated outcomes, subjects were blinded to which dose they were receiving during which cycle. Study details, safety and results from selected efficacy variables have been published elsewhere [20].

In brief, the study comprised three consecutive, flexible, 12-16-week injection cycles, in which the following escalating doses of incobotulinumtoxinA (BoNT-A free from complexing proteins, Xeomin ${ }^{\circ}$, Merz Pharmaceuticals $\mathrm{GmbH}$ ) were administered by intramuscular injection in the same body side on the first day of each injection cycle: cycle 1, a fixed total body dose of $400 \mathrm{U}$ into the upper limb or lower limb only, or split between both; cycle 2, a fixed total body dose of $600 \mathrm{U}$ into the upper limb or lower limb only, or split between both; cycle 3, a total body dose of $800 \mathrm{U}$ split between both upper and lower limbs (maximum dose of $600 \mathrm{U}$ per limb) or a lower total dose of between 600 and $800 \mathrm{U}$, if $800 \mathrm{U}$ was not indicated for clinical or safety reasons.

The study was conducted in accordance with the principles of the Declaration of Helsinki. The protocol was approved by the local institutional review boards and independent ethics committees.

\section{Subjects}

Subjects eligible to participate in the study were male or female and 18-80 years of age with chronic ( $\geq 12$ weeks since the last event leading to spasticity on the side of the body with the selected target clinical pattern diagnosed by a healthcare professional) upper- and lowerlimb spasticity of the same body side due to cerebral causes, and were considered by the investigator to require total body doses of $800 \mathrm{U}$ incobotulinumtoxinA during the course of the study. Subjects with bilateral symptoms due to cerebral or brainstem lesions were eligible if they agreed to be treated on only one side of the body. The area of the target clinical pattern selected for treatment was required to have an Ashworth Scale score $\geq 2$ and a Disability Assessment Scale (DAS) 
score $\geq 2$ (upper limb). Study entry exclusion criteria included: spinal lesions; neurological conditions associated with neuromuscular dysfunction; fixed contracture or muscle hypertonia other than spasticity in the joint associated with the selected target clinical pattern; severe atrophy of muscles associated with the target clinical pattern; prior or planned surgery of the target limb (within 8 weeks) or muscle; treatment with intrathecal baclofen or antispasticity medication with peripheral muscle relaxants within 2 weeks prior to screening; change in antidepressant medication within 4 weeks prior to screening or within the screening period; change in antispastic medication with centrally acting muscle relaxants within 2 weeks prior to screening or within the screening period; infection of planned injection sites; generalized muscle disorders or any other peripheral neuromuscular dysfunction; rheumatic disease in the limbs of the targeted body side; adverse reaction of severe intensity to BoNT-A or BoNT-B lasting $>1$ week within previous 12 months; international normalized ratio (INR) value $>1.5$ and/or a partial thromboplastin time value of $>1.5$-times the upper limit of normal; and forced expiratory volume in $1 \mathrm{~s}\left(\mathrm{FEV}_{1}\right)<70 \%$. Eligibility criteria for injection cycles 2 and 3 included clinical justification for doses of incobotulinumtoxin $\mathrm{A} \geq 600 \mathrm{U}$ (confirmed by a neurologist or rehabilitation physician), absence of infection at the planned injection site, absence of severe weakness of the target muscle that would preclude injection of incobotulinumtoxinA, INR $<1.5$, and $\mathrm{FEV}_{1} \geq 60 \%$.

All subjects were required to provide written informed consent. The subject-reported outcomes, which were evaluated to address the impact of treatment on subject QoL, are detailed below.

\section{Assessment of quality of life}

Quality of life was assessed as an efficacy variable in the TOWER study. Subjects completed the three-level version of EQ-5D [26, 27] at the injection baseline visit of each injection cycle, at 4 weeks post-injection \pm 3 days in each injection cycle, and at the end-of-cycle-3 visit (end of study), giving a total of 7 assessments.

Subjects rated their current state of health on a quantitative visual analog scale (VAS) from 0 (worst) to 100 (best). For each dimension of the EQ-5D descriptive system (Mobility, Self-care, Usual activities, Pain/discomfort and Anxiety/depression), subjects also selected the statement that best described their health state on that day: no problems reported (normal condition, score 1); some problems reported (moderate impairment, score 2); and extreme problems reported (severe impairment, score 3 ).

\section{Statistical analysis}

As this was an exploratory trial, no formal sample size calculation was performed. The efficacy analyses are based on the full analysis set (FAS), which included all subjects who received $\geq 1$ dose of the study medication. Variables were analysed by descriptive statistics. Analysis of EQ-5D scores was performed using observed cases. Mean changes in EQ-5D VAS score from the study baseline to 4 weeks post-treatment in each injection cycle were assessed by the Student's t-test (two-sided) for paired samples. Changes in EQ-5D dimension data from each injection cycle baseline to 4 weeks post-injection were analyzed using frequency tables. In addition, we describe the frequencies of EQ-5D dimension scores at study baseline and the end of injection cycle 3.

\section{Results}

\section{Subjects and exposure}

A total of 155 subjects participated and were treated in the study between May 2012 and September 2014, and were included in the FAS (Additional file 1: Fig. S1). Eighteen (11.6\%) subjects discontinued the study, with three subjects discontinuing after injection in injection cycle 1, 12 subjects after injection in cycle 2, and three subjects after injection in cycle 3. Details of the reasons for study discontinuation have been published previously [20].

Subject characteristics and baseline demographics are summarized in Table 1. The subjects had a mean (standard deviation [SD]) age of 53.7 (13.1) years and the majority were male $(67.1 \%)$. Cerebral vascular disorders were the cause of spasticity for $138(89.0 \%)$ cases, with $85.2 \%$ of subjects having cerebral stroke as the cause. Median time since the diagnosis of the event leading to spasticity of the right and left body sides was 46.5 and 61.4 months, respectively. At study baseline, the mean (SD) REPAS score for assessment of muscle tone of the treated body side was 24.8 (6.7) and the mean (SD) score for all functional domains of the DAS ranged from 2.6 (0.5) to $2.8(0.4)$.

All subjects had spasticity of both the upper and lower limb. One subject had spasticity of both upper limbs and two subjects had spasticity of both lower limbs. The majority of subjects (85.8\%) had previously received treatment with BoNT (type A or B). Median (range) time since the most recent injection of BoNT was 4.4 months (2.7-93.9 months). Depression was reported for $34.8 \%$ of subjects and anxiety was reported for $11.0 \%$ of subjects. In total, 43.9 and $20.6 \%$ of subjects were receiving concomitant psychoanaleptics and psycholeptics, respectively.

Seventy-one $(45.8 \%)$ subjects were treated on the right side of the body and 84 (54.2\%) subjects were treated on the left side. Most subjects received the scheduled dose in each injection cycle $(91.0 \%$ [141/155] received $400 \mathrm{U}$ in cycle $1 ; 90.8 \%$ [138/152] received $600 \mathrm{U}$ in cycle 2; and $82.9 \%$ [116/140] received $800 \mathrm{U}$ in cycle 3). A total of $140(90.3 \%)$ subjects received all three injections. 
Table 1 Subject demographics and baseline characteristics (FAS)

\begin{tabular}{ll}
\hline Characteristic & $\begin{array}{l}\text { Subjects } \\
N=155\end{array}$ \\
\hline Age (years), mean (SD) & $53.7(13.1)$ \\
Sex, $n$ (\%) & $104(67.1)$ \\
Male & \\
Race, $n$ (\%) & $129(83.2)$ \\
White & $4(2.6)$ \\
Black/African American & $3(1.9)$ \\
Other & $19(12.3)$ \\
Missing & $27.5(4.9)$ \\
BMI (kg/m²), mean (SD) & \\
Cause of spasticity, $n$ (\%) & $87(56.1)$ \\
Ischemic stroke & $45(29.0)$ \\
Hemorrhagic stroke & $11(7.1)$ \\
Traumatic brain injury & $6(3.9)$ \\
Other cerebral vascular disorders & $4(2.6)$ \\
Brain tumor & $2(1.3)$ \\
Cerebral palsy &
\end{tabular}

Time since diagnosis of event leading to spasticity (months), median (range)

\begin{tabular}{ll} 
Left body side; $n=81$ & $61.4(2.8-428.9)$ \\
Right body side; $n=68$ & $46.5(3.7-372.8)$ \\
REPAS $^{\text {a }}$ score at study baseline, mean (SD) & $24.8(6.7)$ \\
DAS $^{\text {b }}$ score at study baseline, mean (SD) & \\
Principle therapeutic target & $2.6(0.5)$ \\
Hygiene & $2.6(0.5)$ \\
Dressing & $2.6(0.5)$ \\
Limb position & $2.6(0.5)$ \\
Pain & $2.8(0.4)$ \\
\hline
\end{tabular}

REPAS score of the treated body side consisting of the sum scores for 13 items, each rated using the Ashworth Scale from 0 to 4, ranging from 0 (no resistance to passive movement for any of the items) to 52 (limbs rigid to passive movement for all items)

${ }^{b}$ DAS score, ranging from 0 (no disability) to 3 (severe disability, normal activities limited)

BMI body mass index, DAS Disability Assessment Scale, FAS full analysis set, REPAS Resistance to Passive Movement Scale, SD standard deviation

\section{Assessment of quality of life EQ-5D VAS}

Compared with study baseline, there was an improvement in mean EQ-5D VAS score 4 weeks post-injection in cycle 1 , which was sustained with subsequent injections. The mean (SD) EQ-5D VAS score improved from 59.9 (18.9) at the study baseline to 66.7 (17.6) 4 weeks post-injection in cycle 1, and improved further to 70.5 (16.7) at the end of cycle 3 (Fig. 1a), corresponding to a mean (95\% confidence interval $[\mathrm{CI}])$ change of $10.5(7.6,13.4)$ from study baseline to the end of cycle $3(p<0.0001$, Student's t-test for paired samples; Fig. 1b). The mean (SD) change in EQ-5D VAS score from the study baseline to 4 weeks post-treatment was $6.7(14.1)$ in cycle 1, $9.6(16.3)$ in cycle 2 , and 8.6 (17.0) in cycle $3(p<0.0001$ for all versus study baseline, Student's t-test for paired samples).

\section{EQ-5D dimension ratings}

Among those subjects who had a change in the rating of their condition at 4 weeks post-injection, a greater proportion of subjects had 'improvement' than 'worsening' for all dimensions across all injection cycles, with the exception of Self-care in injection cycle 2 (Table 2).

The proportion of subjects with 'improvement' was $\geq 10 \%$ greater than that with 'worsening' of their condition for Mobility in injection cycle 1, Pain/discomfort for all injection cycles, and Anxiety/depression in injection cycle 1 . At 4 weeks post-injection, the majority of subjects had 'no change' in the rating of their condition within each injection cycle for individual EQ-5D dimensions (Table 2).

From the study baseline to the end of injection cycle 3, the proportion of subjects with improvements in EQ-5D ratings was greater than the proportion of subjects with worsening of ratings for all dimensions: Mobility, 11.4\% versus 2.9\%; Self-care, $21.4 \%$ versus $7.1 \%$; Usual activities, $24.3 \%$ versus 5.0\%; Pain/discomfort, $30.7 \%$ versus 9.3\%; Anxiety/depression, 25.0\% versus 9.3\% (Fig. 2). The proportions of subjects rating their condition as 'normal', 'moderate impairment', or 'severe impairment' for each dimension at study baseline and the end of injection cycle 3 are shown in Table 3.

Across all dimensions, compared with study baseline, there was an increase in the proportion of subjects rating their condition as 'normal' at the end of injection cycle 3. This improvement was $>10 \%$ for Pain/discomfort $(34.2 \%$ at baseline to $51.4 \%$ at end of injection cycle 3 ) and Anxiety/depression (46.5\% at baseline to $58.6 \%$ at end of injection cycle 3). The proportion of subjects with 'severe impairment' was reduced by $\geq 46 \%$ for all EQ-5D dimensions at the end of injection cycle 3 compared with study baseline; however, this condition rating applied to a small proportion of subjects overall ( $\leq 20 \%$ at baseline for all dimensions; Table 3 and Fig. 3).

\section{Discussion}

TOWER was the first prospective clinical study to demonstrate that dose escalation with total body doses of incobotulinumtoxinA up to $800 \mathrm{U}$ enables treatment in a greater number of muscles/spasticity patterns, without compromising safety or tolerability [20]. Consistent with the observed improvements in muscle tone and better goal attainment associated with dose escalation from 400 to $800 \mathrm{U}$ of incobotulinumtoxinA presented previously [20], we demonstrated the beneficial effects of incobotulinumtoxinA on QoL among this study population. There were sustained improvements in QoL across 

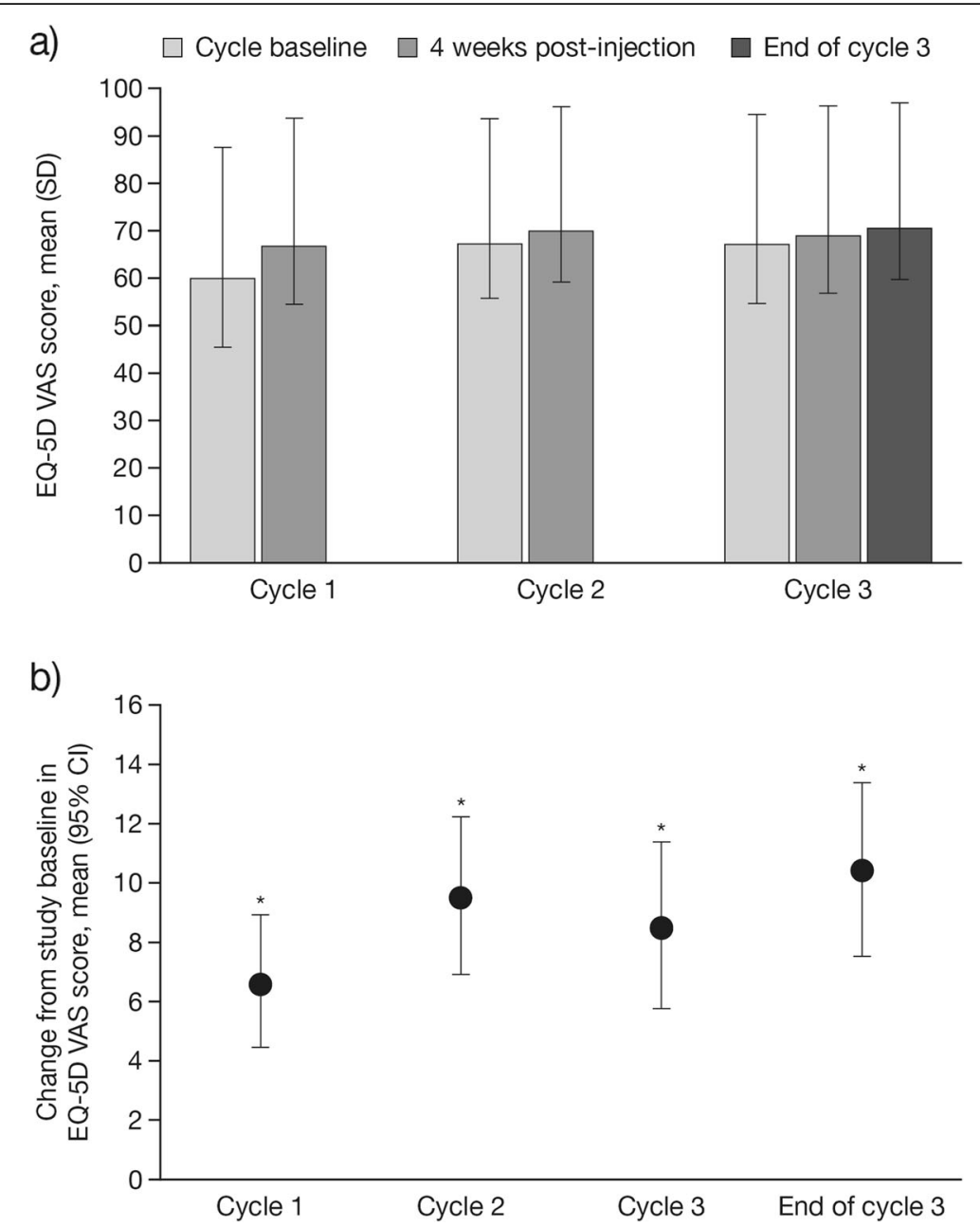

Fig. 1 a Mean (SD), and b mean (95\% Cl) change in EQ-5D VAS scores (FAS). a) Time points: at injection cycle baseline and 4 weeks post-injection in each injection cycle and at the end of injection cycle 3. b) Time points: from the study baseline to 4 weeks post-injection in each injection cycle and to the end of injection cycle 3. Positive values indicate improvement. ${ }^{*} p<0.0001$ compared with the study baseline visit in injection cycle 1, Student's t-test for paired samples. Cl, confidence interval; EQ-5D, EuroQol 5-dimensions questionnaire, three-level; FAS, full analysis set; SD, standard deviation; VAS, visual analog scale

all three injection cycles, as well as improvements in self-assessed health status (EQ-5D VAS) across injection cycles. Among those subjects who had a change in the rating of their condition, at the end of injection cycle 3 a greater proportion of subjects had improvement of ratings from injection cycle baseline than worsening of ratings for all dimensions of the EQ-5D. Similarly, the proportion of subjects with a rating of 'normal condition' in each of the five EQ-5D dimensions was greater and the proportion with 'severe impairment' to QoL was lower at the end of injection cycle 3, compared with ratings at study baseline. Of note, there was $a \geq 46 \%$ decrease in the proportion of subjects with 'severe impairment' for all five EQ-5D dimensions by the end of injection cycle 3 . However, the numbers of subjects with ratings of 'severe impairment' were low, particularly for the Mobility dimension. The factors that may identify which subjects will experience QoL improvements that can be measured using EQ-5D are currently unknown. Furthermore, as this was an exploratory trial without a parallel fixed-dose comparator arm or placebo control, these QoL results are descriptive; randomized controlled studies are required to confirm the findings.

Few studies have investigated the effect of BoNT-A treatment on subjects' QoL $[1,3]$. In a non-interventional study, incobotulinumtoxinA in combination with conventional therapy (oral antispasticity medication, physiotherapy, and occupational therapy) significantly improved QoL (assessed by 12-Item Short Form Health Survey score) compared with baseline during 1-year treatment of post-stroke upper-limb spasticity [12]. The TOWER study is, to our knowledge, the first to provide some evidence of an improvement in QoL using escalating doses of BoNT-A for the simultaneous treatment of upper- and lower-limb 
Table 2 Change in EQ-5D dimensions from injection cycle baseline to 4 weeks post-injection (FAS)

\begin{tabular}{|c|c|c|c|c|c|c|}
\hline Dimension & Injection cycle & $N$ & Nobs & Improvement, $n(\%)$ & No change, $n(\%)$ & Worsening, $n(\%)$ \\
\hline \multirow[t]{3}{*}{ Mobility } & 1 & 155 & 155 & $18(11.6)$ & $135(87.1)$ & $2(1.3)$ \\
\hline & 2 & 152 & 149 & $11(7.2)$ & $136(89.5)$ & $2(1.3)$ \\
\hline & 3 & 140 & 138 & $6(4.3)$ & $128(91.4)$ & $4(2.9)$ \\
\hline \multirow[t]{3}{*}{ Self-care } & 1 & 155 & 155 & 19 (12.3) & $123(79.4)$ & $13(8.4)$ \\
\hline & 2 & 152 & 148 & $7(4.6)$ & $127(83.6)$ & $14(9.2)$ \\
\hline & 3 & 140 & 138 & $11(7.9)$ & $121(86.4)$ & $6(4.3)$ \\
\hline \multirow[t]{3}{*}{ Usual activities } & 1 & 155 & 155 & $20(12.9)$ & $126(81.3)$ & $9(5.8)$ \\
\hline & 2 & 152 & 148 & $18(11.8)$ & $116(76.3)$ & $14(9.2)$ \\
\hline & 3 & 140 & 138 & $8(5.7)$ & $126(90.0)$ & $4(2.9)$ \\
\hline \multirow[t]{3}{*}{ Pain/discomfort } & 1 & 155 & 155 & $40(25.8)$ & $105(67.7)$ & $10(6.5)$ \\
\hline & 2 & 152 & 149 & $32(21.1)$ & $105(69.1)$ & $12(7.9)$ \\
\hline & 3 & 140 & 138 & $29(20.7)$ & $102(72.9)$ & $7(5.0)$ \\
\hline \multirow[t]{3}{*}{ Anxiety/depression } & 1 & 155 & 155 & $27(17.4)$ & $119(76.8)$ & $9(5.8)$ \\
\hline & 2 & 152 & 149 & $18(11.8)$ & $121(79.6)$ & $10(6.6)$ \\
\hline & 3 & 140 & 138 & 18 (12.9) & $111(79.3)$ & $9(6.4)$ \\
\hline
\end{tabular}

EQ-5D EuroQol 5-dimensions questionnaire, three-level, FAS full analysis set, $N$ number of subjects treated, Nobs number of observed cases

spasticity. Dose escalation allowed the physician the flexibility to increase the dose per muscle within the defined dose range, and enabled the treatment of more muscles and clinical patterns according to the needs and treatment goals of the individual subject [20], and this may have contributed to improvement in QoL.

The EQ-5D has previously been validated in subjects following stroke [28], who form the largest proportion of the TOWER study population. Differences in EQ-5D scores between stroke survivors with and without spasticity met the minimal clinically important differences previously established for other validated diseases, potentially supporting the use of EQ-5D as a measure of QoL in this population [4]. However, the use of EQ-5D may be considered a limitation of this study, since it is not validated for use in spasticity.

The three-level EQ-5D, which was the only version available at the outset of this study, may lack the sensitivity required to capture incremental but meaningful changes in QoL in these subjects. For example, a

\section{Improvement $\square$ Worsening}

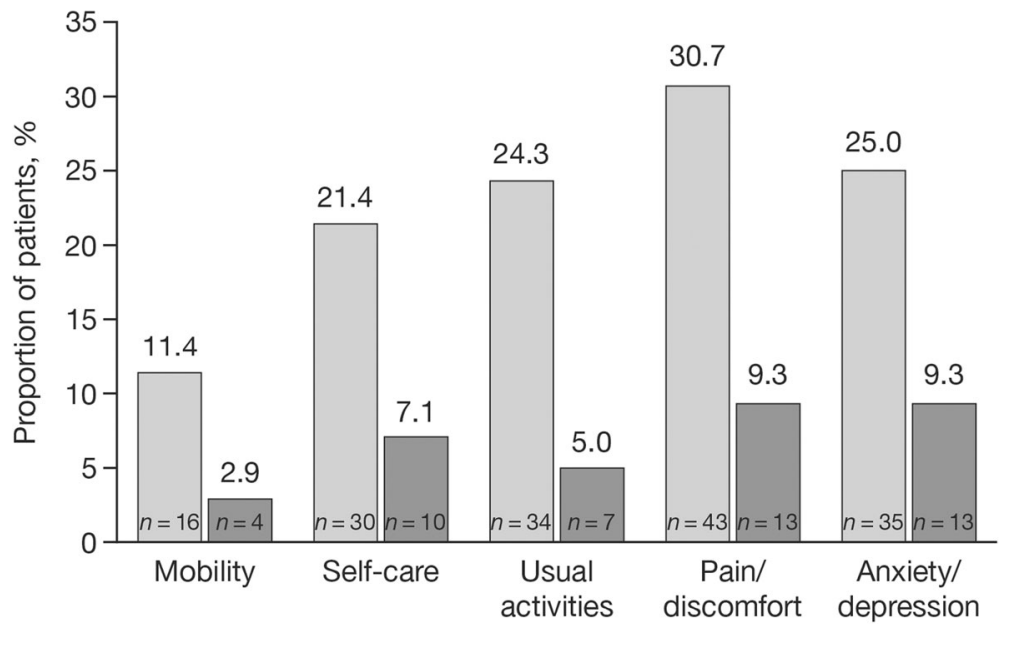

EQ-5D dimension

Fig. 2 Subjects with improvement or worsening of EQ-5D ratings in all dimensions (FAS). Time points: from study baseline to the end of injection cycle $3(N=138)$. EQ-5D, EuroQol 5-dimensions questionnaire, three-level; FAS, full analysis set; $n$, number of observed cases 
Table 3 EQ-5D dimension score frequency at study baseline and end of cycle 3 (FAS)

\begin{tabular}{|c|c|c|c|c|c|c|}
\hline \multirow[t]{2}{*}{ Dimension } & \multirow[t]{2}{*}{ Visit } & \multirow[t]{2}{*}{$N$} & \multirow[t]{2}{*}{ Nobs } & \multicolumn{3}{|c|}{ Frequency, $n$ (\%) subjects } \\
\hline & & & & $\begin{array}{l}\text { Normal condition } \\
\text { Notis }\end{array}$ & $\begin{array}{l}2 \\
\text { Moderate impairment }\end{array}$ & $\begin{array}{l}3 \\
\text { Severe impairment }\end{array}$ \\
\hline \multirow[t]{2}{*}{ Mobility } & Baseline & 155 & 155 & $12(7.7)$ & $139(89.7)$ & $4(2.6)$ \\
\hline & End of injection cycle 3 & 140 & 137 & $23(16.4)$ & $112(80.0)$ & $2(1.4)$ \\
\hline \multirow[t]{2}{*}{ Self-care } & Baseline & 155 & 155 & $30(19.4)$ & $96(61.9)$ & $29(18.7)$ \\
\hline & End of injection cycle 3 & 140 & 137 & $33(23.6)$ & $93(66.4)$ & $11(7.9)$ \\
\hline \multirow[t]{2}{*}{ Usual activities } & Baseline & 155 & 155 & $11(7.1)$ & $113(72.9)$ & $31(20.0)$ \\
\hline & End of injection cycle 3 & 140 & 137 & $22(15.7)$ & $103(73.6)$ & $12(8.6)$ \\
\hline \multirow[t]{2}{*}{ Pain/discomfort } & Baseline & 155 & 155 & $53(34.2)$ & $85(54.8)$ & $17(11.0)$ \\
\hline & End of injection cycle 3 & 140 & 137 & $72(51.4)$ & $60(42.9)$ & $5(3.6)$ \\
\hline \multirow[t]{2}{*}{ Anxiety/depression } & Baseline & 155 & 155 & $72(46.5)$ & $69(44.5)$ & $14(9.0)$ \\
\hline & End of injection cycle 3 & 140 & 137 & $82(58.6)$ & $53(37.9)$ & $2(1.4)$ \\
\hline
\end{tabular}

EQ-5D EuroQol 5-dimensions questionnaire, three-level, FAS full analysis set, $N$ number of subjects treated, Nobs number of observed cases

previous randomized clinical trial of BoNT-A that used the EQ-5D questionnaire to measure QoL in subjects with upper-limb spasticity due to stroke did not demonstrate any significant improvement in the Mobility, Self-care, or Usual activities dimensions up to 12 months post-treatment [29]. Although significant improvements were observed at some time points for the Pain/discomfort and Anxiety/depression dimensions, the magnitude of these changes was negligible and the clinical significance was unclear [29]. Pain/discomfort may be most successfully alleviated with high-dose treatment. Therefore, it may be noteworthy that Pain/discomfort and Anxiety/depression were also the dimensions for which we observed the highest frequency of subjects with improvement and the greatest proportion of subjects rating their condition as 'normal' at the end of injection cycle 3. While these findings might suggest that treatment with BoNT-A has a positive impact on these aspects of QoL, it is also possible that these are the dimensions most likely to be influenced by the clinical trial environment where subjects are receiving highly structured spasticity management from a specialist team. Notably, the comparatively low proportion of subjects who experienced an improvement in Mobility, Self-care, and Usual activities is likely to reflect a high degree of underlying motor deficits in this chronic population, as demonstrated by the high REPAS and DAS scores at study baseline. This suggests that subjects experiencing painful spasticity, but with sufficient underlying motor function, may experience greater QoL improvements with high-dose

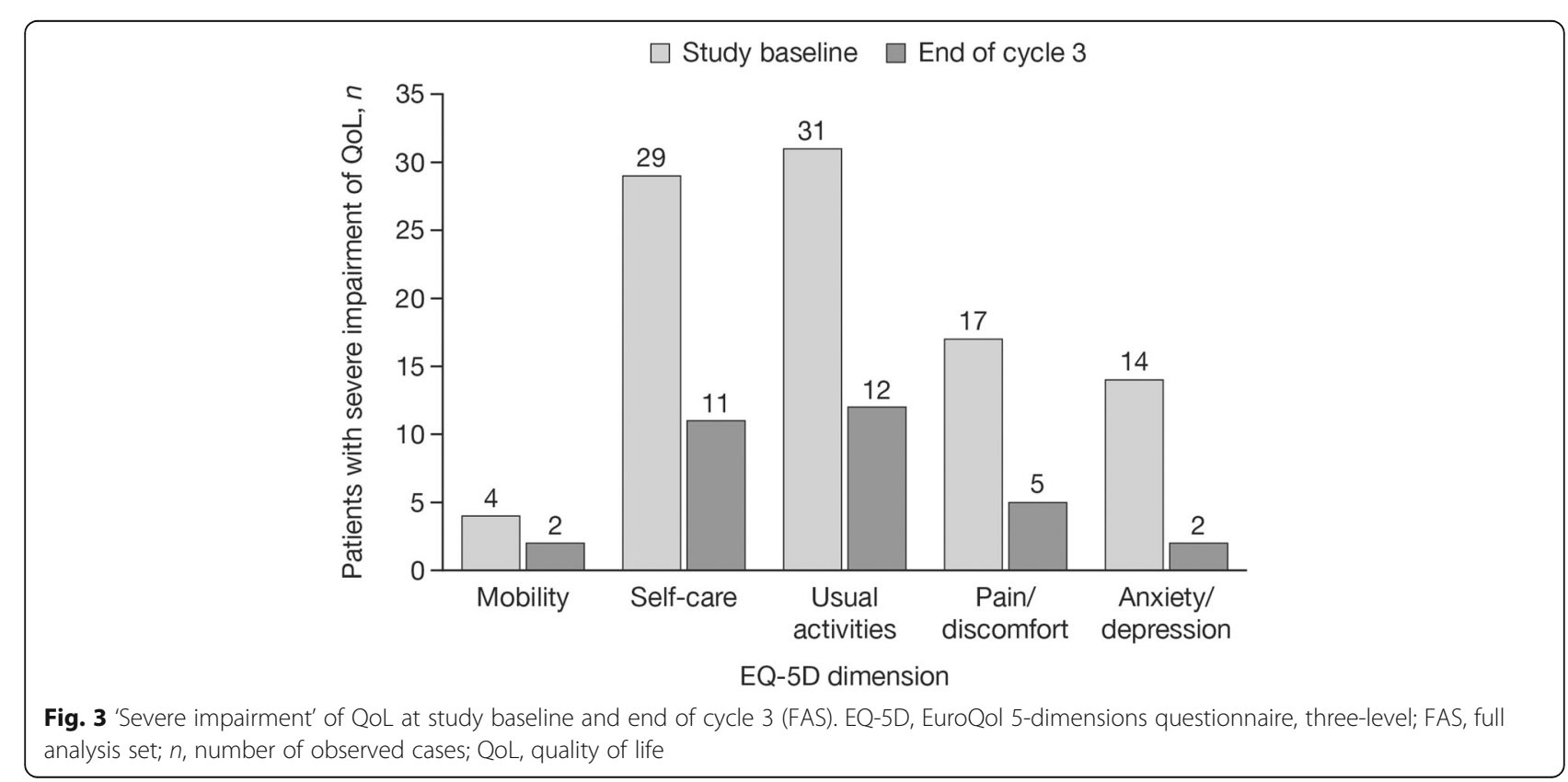


incobotulinumtoxinA, compared with subjects with significant functional impairment.

Interestingly, the greatest proportion of subjects with improvements in all EQ-5D dimensions occurred following treatment with $400 \mathrm{U}$ in the first injection cycle, with sustained improvement in subsequent injection cycles, suggesting a ceiling effect, which has also been observed in previous studies using the three-level EQ-5D [30]. Future studies of QoL in subjects with spasticity may benefit from use of the five-level EQ-5D [31], which incorporates additional terms to describe health status and is expected to offer better sensitivity and discriminatory capacity than the EQ-5D [31, 32]. Novel tools, such as the Spasticity-Related Quality-of-Life Tool (SQoL-6D), are in development specifically for spasticity and may also be of value for future research once validated [33]. Given the limited assessment tools available, it is unsurprising that there is a paucity of data on QoL in subjects with chronic spasticity. In particular, the lack of normative QoL data for subjects with upper- and lower-limb spasticity is a major limitation when interpreting changes in QoL as a result of BoNT-A intervention. It is intended that the results reported here will serve as a valuable starting point for further research in this field.

\section{Conclusions}

The safety and efficacy of BoNT-A formulations for the treatment of upper- and lower-limb spasticity are well established, and these formulations form a key component of the multidisciplinary management of this condition [9-19, 34, 35]. A subject-centered approach to management of spasticity, as shown for incobotulinumtoxinA, is important to help subjects achieve their individual goals and also improve their QoL [6]. Consistent with previous reports [21,36-38], results of the TOWER study showed that treatment with total body doses of incobotulinumtoxinA up to $800 \mathrm{U}$ is well tolerated, and no new safety concerns were identified for higher cumulative doses [20]. Using higher doses of incobotulinumtoxinA enables simultaneous treatment of more clinical patterns of upper- and lower-limb spasticity that is very likely to also contribute to improvement in multiple aspects of subjects' QoL, supporting its potential role in the rehabilitation of subjects with multifocal upper- and lower-limb spasticity.

\section{Supplementary information}

Supplementary information accompanies this paper at https://doi.org/10. 1186/s12955-020-01304-4.

Additional file 1: Fig. S1. Subject disposition.

\section{Abbreviations}

BMI: Body mass index; BoNT-A: Botulinum neurotoxin type A; BoNT-B: Botulinum neurotoxin type B; Cl: Confidence interval; DAS: Disability Assessment Scale; EPAS: Resistance to Passive Movement Scale;
EQ-5D: EuroQol 5-dimensions questionnaire, three-level; FAS: Full analysis set; FEV $V_{1}$ : Forced expiratory volume in $1 \mathrm{~s}$; INR: International normalized ratio; QoL: Quality of life; SD: Standard deviation; SQoL-6D: Spasticity-Related Quality-of-Life Tool; TOWER: The Titration study in IOWer and uppER limb spasticity; VAS: Visual analog scale

\section{Acknowledgements}

The authors wish to thank the subjects and study investigators. This study was supported by Merz Pharmaceuticals GmbH, Frankfurt am Main, Germany Medical writing support, under the direction of the authors, was provided by Claire Cairney, PhD, CMC Connect, McCann Health Medical Communications and Kirsteen Munn, PhD, on behalf of CMC Connect, funded by Merz Pharmaceuticals GmbH, in accordance with Good Publication Practice (GPP3) guidelines.

\section{Authors' contributions}

DD and DMS contributed equally to this work. KF analyzed the data and is guarantor of this article. TR, LM, DB, and DMS implemented the trial in Norway, Portugal, France, and the USA, respectively. PK, JW, and DD implemented the trial in Germany. BF-B wrote the statistical analysis plan and analyzed the data. AS and OS analyzed the data. All authors contributed to interpretation of the data, revised the draft manuscript, and approved the final version.

\section{Funding}

This study was supported by Merz Pharmaceuticals GmbH, Frankfurt am Main, Germany.

\section{Availability of data and materials}

Additional data for the TOWER study are available to researchers, and can be found in the ClinicalTrials.gov record (NCT01603459).

\section{Ethics approval and consent to participate}

The study was conducted in accordance with the principles of the Declaration of Helsinki. The protocol was approved by the local institutional review boards and independent ethics committees: University of Calgary, Conjoint Health Research Ethics Board, Calgary, AB, Canada; Health Research Ethics Board, University of Alberta, Edmonton, AB, Canada; Committee of Protection for People Ile de France VIII, Ambroise Paré Hospital, Boulogne-Billancourt, France: Ethik-Kommission der Landesärztekammer Brandenburg, Cottbus, Germany; Chairman of the Ethics Committee, Comitato Etico Ospedale Valduce, Como, Italy; Comitato Etico Locale per la Sperimentazione Clinica, Azienda Ospedaliera Luigi Sacco di Milano, Milan, Italy; EC Secretariat for Clinical Trials, Azienda Ospedaliera Universitaria Integrata Verona, Verona, Italy; Regional Ethics Committee, REK vest, Haukeland Universitetssykehus, Bergen, Norway; Ethics committee for clinical research (CEIC), Lisbon, Portugal; Hospital Universitari de Bellvitge, Clinical research ethics committee, L'Hospitalet de Llobregat, Llobregat, Spain; Cleveland Clinic foundation IRB, Cleveland, OH, USA; Copernicus Group IRB, Durham, NC, USA; Indiana University IRB, Indianapolis, IN, USA; Medical College of Wisconsin, Froedtert Hospital, IRB, Milwaukee, WI, USA; BRANY IRB, Lake Success, NY, USA.

All subjects provided informed consent.

\section{Consent for publication}

Not applicable.

\section{Competing interests}

KF has received research grants from Ipsen and Merz Pharmaceuticals, and has received sponsorship from Allergan, Ipsen, and Merz Pharmaceuticals to attend conferences and advisory board meetings in the EU. TR has served as a consultant for Allergan, Ipsen, Medtronic, and Merz Pharmaceuticals. LM has received research grants from Merz Pharmaceuticals. PK has received research grants from Ipsen, Medtronic, and Merz Pharmaceuticals, and has received sponsorship from Ipsen, Medtronic, and Merz Pharmaceuticals to attend conferences and/or advisory board meetings in the EU. JW has received research grant support from, and served as a consultant for, Allergan, Ipsen, Medtronic, and Merz Pharmaceuticals. DB has served as a consultant for Allergan, Almirall, Ipsen, Medtronic, and Merz Pharmaceuticals. AS and BF-B are employees of Merz Pharmaceuticals. OS is a former employee of Merz Pharmaceuticals. DD has received payments from AbbVie, Allergan, Bayer, IAB-Interdisciplinary Working Group for Movement Disorders, 
Ipsen, Medtronic, Merz Pharmaceuticals, Sintetica, Syntaxin, and UCB, and is a shareholder of Allergan. DD also holds patents on botulinum toxin and botulinum toxin therapy. DMS has received research grant support from, and served as a consultant for, Allergan, Ipsen, and Merz Pharmaceuticals.

\section{Author details}

'Gailtal-Klinik, Hermagor, Austria. ${ }^{2}$ Haukeland University Hospital, Bergen, Norway. ${ }^{3}$ Centro Hospitalar de Lisboa Central, Lisbon, Portugal. ${ }^{4}$ Kliniken Beelitz GmbH, Beelitz-Heilstätten, Beelitz, Germany. ${ }^{5}$ Vivantes Hospital Spandau, Berlin, Germany. ${ }^{6}$ Raymond-Poincaré Hospital, AP-HP, University of Versailles Saint Quentin, Garches, France. ${ }^{7}$ Merz Pharmaceuticals GmbH, Frankfurt am Main, Germany. ${ }^{8}$ Formerly of Merz Pharmaceuticals GmbH, Frankfurt am Main, Germany. ${ }^{9}$ Hannover Medical School, Hannover, Germany.

${ }^{10}$ Icahn School of Medicine at Mount Sinai, New York, New York, USA

Received: 14 August 2019 Accepted: 20 February 2020

Published online: 04 March 2020

\section{References}

1. Baker JA, Pereira G. The efficacy of Botulinum toxin a for limb spasticity on improving activity restriction and quality of life: a systematic review and meta-analysis using the GRADE approach. Clin Rehabil. 2016;30(6):549-58.

2. Doan QV, Brashear A, Gillard PJ, Varon SF, Vandenburgh AM, Turkel CC, et al. Relationship between disability and health-related quality of life and caregiver burden in patients with upper limb poststroke spasticity. PM\&R. 2012:4(1):4-10.

3. McCrory P, Turner-Stokes L, Baguley IJ, De Graaff S, Katrak P, Sandanam J, et al. Botulinum toxin a for treatment of upper limb spasticity following stroke: a multi-Centre randomized placebo-controlled study of the effects on quality of life and other person-centred outcomes. J Rehabil Med. 2009; 41(7):536-44.

4. Gillard PJ, Sucharew H, Kleindorfer D, Belagaje S, Varon S, Alwell K, et al. The negative impact of spasticity on the health-related quality of life of stroke survivors: a longitudinal cohort study. Health Qual Life Outcomes. 2015;13:159.

5. Martin A, Abogunrin S, Kurth H, Dinet J. Epidemiological, humanistic, and economic burden of illness of lower limb spasticity in adults: a systematic review. Neuropsychiatr Dis Treat. 2014;10:111-22.

6. Barnes M, Kocer S, Murie Fernandez M, Balcaitiene J, Fheodoroff K. An international survey of patients living with spasticity. Disabil Rehabil. 2017; 39(14):1428-34.

7. Rychlik R, Kreimendahl F, Schnur N, Lambert-Baumann J, Dressler D. Quality of life and costs of spasticity treatment in German stroke patients. Health Econ Rev. 2016;6(1):27.

8. Esquenazi A, Novak I, Sheean G, Singer BJ, Ward AB. International consensus statement for the use of botulinum toxin treatment in adults and children with neurological impairments-introduction. Eur J Neurol. 2010;17(Suppl 2):1-8.

9. Simpson DM, Hallett M, Ashman EJ, Comella CL, Green MW, Gronseth GS, et al. Practice guideline update summary: botulinum neurotoxin for the treatment of blepharospasm, cervical dystonia, adult spasticity, and headache: report of the guideline development Subcommittee of the American Academy of neurology. Neurology. 2016;86(19):1818-26.

10. Bakheit AMO, Fedorova NV, Skoromets AA, Timerbaeva SL, Bhakta BB, Coxon $L$. The beneficial antispasticity effect of botulinum toxin type $a$ is maintained after repeated treatment cycles. J Neurol Neurosurg Psychiatry. 2004;75(11):1558-61

11. Barnes M, Schnitzler A, Medeiros L, Aguilar M, Lehnert-Batar A, Minnasch P. Efficacy and safety of NT 201 for upper limb spasticity of various etiologies - a randomized parallel-group study. Acta Neurol Scand. 2010;122(4):295-302.

12. Dressler D, Rychlik R, Kreimendahl F, Schnur N, Lambert-Baumann J. Longterm efficacy and safety of incobotulinumtoxinA and conventional treatment of poststroke arm spasticity: a prospective, non-interventional, open-label, parallel-group study. BMJ Open. 2015;5(12):e009358.

13. Dunne JW, Gracies JM, Hayes M, Zeman B, Singer BJ. A prospective, multicentre, randomized, double-blind, placebo-controlled trial of onabotulinumtoxinA to treat plantarflexor/invertor overactivity after stroke. Clin Rehabil. 2012;26(9):787-97

14. Elovic EP, Brashear A, Kaelin D, Liu J, Millis SR, Barron R, et al. Repeated treatments with botulinum toxin type a produce sustained decreases in the limitations associated with focal upper-limb poststroke spasticity for caregivers and patients. Arch Phys Med Rehabil. 2008;89(5):799-806.
15. Elovic EP, Munin MC, Kaňovský P, Hanschmann A, Hiersemenzel R, Marciniak C. Randomized, placebo-controlled trial of incobotulinumtoxinA for upperlimb post-stroke spasticity. Muscle Nerve. 2016;53(3):415-21.

16. Gracies JM, Brashear A, Jech R, McAllister $P$, Banach $M$, Valkovic $P$, et al. Safety and efficacy of abobotulinumtoxinA for hemiparesis in adults with upper limb spasticity after stroke or traumatic brain injury: a double-blind randomised controlled trial. Lancet Neurol. 2015;14(10):992-1001.

17. Pittock SJ, Moore AP, Hardiman O, Ehler E, Kovac M, Bojakowski J, et al. A double-blind randomised placebo-controlled evaluation of three doses of botulinum toxin type a (Dysport $\left.{ }^{\oplus}\right)$ in the treatment of spastic equinovarus deformity after stroke. Cerebrovasc Dis. 2003;15(4):289-300.

18. Kaji R, Osako Y, Suyama K, Maeda T, Uechi Y, Iwasaki M. Botulinum toxin type a in post-stroke upper limb spasticity. Curr Med Res Opin. 2010;26(8):1983-92.

19. Kaňovský P, Slawek J, Denes Z, Platz T, Sassin I, Comes G, et al. Efficacy and safety of botulinum neurotoxin NT 201 in poststroke upper limb spasticity. Clin Neuropharmacol. 2009;32(5):259-65.

20. Wissel J, Bensmail D, Ferreira JJ, Molteni F, Satkunam L, Moraleda S, et al. Safety and efficacy of incobotulinumtoxinA doses up to $800 \mathrm{U}$ in limb spasticity: the TOWER study. Neurology. 2017;88(14):1321-8.

21. Dressler D, Saberi FA, Kollewe K, Schrader C. Safety aspects of incobotulinumtoxinA high-dose therapy. J Neural Transm (Vienna). 2015; 122(2):327-33.

22. Merz Pharma UK Ltd. XEOMIN ${ }^{\otimes}(50 / 100 / 200)$ Summary of Product Characteristics. http://www.medicines.org.uk/emc/medicine/24582. Accessed 17 May 2019.

23. Merz Pharmaceuticals LLC. Highlights of prescribing information - Xeomin ${ }^{\oplus}$. https://www.accessdata.fda.gov/drugsatfda_docs/label/2019/125360s074lbl. pdf. Accessed 17 May 2019.

24. Platz T, Vuadens P, Eickhof C, Arnold P, Van Kaick S, Heise K. REPAS, a summary rating scale for resistance to passive movement: item selection, reliability and validity. Disabil Rehabil. 2008;30(1):44-53.

25. Brashear A, Gordon MF, Elovic E, Kassicieh VD, Marciniak C, Do M, et al. Intramuscular injection of botulinum toxin for the treatment of wrist and finger spasticity after a stroke. N Engl J Med. 2002;347(6):395-400.

26. EuroQoL Group. EuroQol - a new facility for the measurement of healthrelated quality of life. Health Policy. 1990;16(3):199-208.

27. van Reenen M, Oppe M. EQ-5D-3L User Guide. Basic information on how to use the EQ-5D-3L instrument. https://eurogol.org/eg-5d-instruments/. Accessed 17 May 2019.

28. Hunger M, Sabariego C, Stollenwerk B, Cieza A, Leidl R. Validity, reliability and responsiveness of the EQ-5D in German stroke patients undergoing rehabilitation. Qual Life Res. 2012;21(7):1205-16.

29. Shaw L, Rodgers H, Price C, van Wijk F, Shackley P, Steen N, et al. BoTULS: a multicentre randomised controlled trial to evaluate the clinical effectiveness and cost-effectiveness of treating upper limb spasticity due to stroke with botulinum toxin type a. Health Technol Assess. 2010;14(26):1-113.

30. Pattanaphesaj J, Thavorncharoensap M. Measurement properties of the EQ5D-5L compared to EQ-5D-3L in the Thai diabetes patients. Health Qual Life Outcomes. 2015:13:14

31. Herdman M, Gudex C, Lloyd A, Janssen M, Kind P, Parkin D, et al. Development and preliminary testing of the new five-level version of EQ-5D (EQ-5D-5L). Qual Life Res. 2011;20(10):1727-36.

32. van Reenen M, Janssen B. EQ-5D-5L User Guide: basic information on how to use the EQ-5D-5L instrument. https://euroqol.org/eq-5d-instruments/. Accessed May 172019.

33. Turner-Stokes L, Ashford S, Jacinto J, Maisonobe P, Balcaitiene J, Fheodoroff K. Impact of integrated upper limb spasticity management including botulinum toxin a on patient-centred goal attainment: rationale and protocol for an international prospective, longitudinal cohort study (ULIS-III). BMJ Open. 2016;6(6):e011157.

34. Wissel J, Ward AB, Erztgaard P, Bensmail D, Hecht MJ, Lejeune TM, et al. European consensus table on the use of botulinum toxin type a in adult spasticity. J Rehabil Med. 2009;41(1):13-25.

35. Esquenazi A, Albanese A, Chancellor MB, Elovic E, Segal KR, Simpson DM, et al. Evidence-based review and assessment of botulinum neurotoxin for the treatment of adult spasticity in the upper motor neuron syndrome. Toxicon. 2013;67:115-28.

36. Dressler D. Routine use of Xeomin in patients previously treated with Botox: long term results. Eur J Neurol. 2009;16(Suppl 2):2-5.

37. Intiso D, Simone V, Di Rienzo F, larossi A, Pazienza L, Santamato A, et al. High doses of a new botulinum toxin type a (NT-201) in adult patients with 
severe spasticity following brain injury and cerebral palsy. NeuroRehabilitation. 2014;34(3):515-22.

38. Santamato A, Panza F, Ranieri M, Frisardi V, Micello MF, Filoni S, et al. Efficacy and safety of higher doses of botulinum toxin type a NT 201 free from complexing proteins in the upper and lower limb spasticity after stroke. J Neural Transm (Vienna). 2013;120(3):469-76.

\section{Publisher's Note}

Springer Nature remains neutral with regard to jurisdictional claims in published maps and institutional affiliations.

Ready to submit your research? Choose BMC and benefit from:

- fast, convenient online submission

- thorough peer review by experienced researchers in your field

- rapid publication on acceptance

- support for research data, including large and complex data types

- gold Open Access which fosters wider collaboration and increased citations

- maximum visibility for your research: over $100 \mathrm{M}$ website views per year

At $B M C$, research is always in progress.

Learn more biomedcentral.com/submissions 